\title{
Helicopter Landing Sites Identification depending on Slope, Landing Site Dimension and Shape
}

\author{
Eva Mertova ${ }^{\mathrm{a}}$ and Martin Bures ${ }^{\mathrm{b}}$ \\ eva.mertova@unob.cz, martin.bures@army.cz

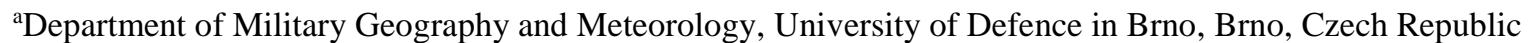

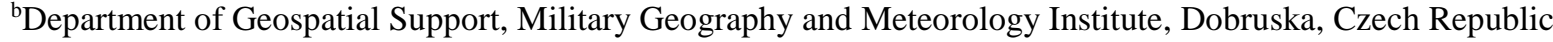

\begin{abstract}
The identification of the Helicopter Landing Sites (HLS) needs complex analysis of the terrain considering a lot of aspects. One of the unconditional aspects in this case is the slope of ground, therefore the HLS identification depending on slope, landing site dimension and shape was conducted. This paper describes the development of the tool for the HLS identification depending only on the relief, but no other objects on the earth's surface. At the end of the paper, the possible improvements of the tools are stated.
\end{abstract}

Keywords: helicopter landing site, HLS, slope, dimension, shape, geospatial analysis

\section{Introduction}

Nowadays, helicopters are used in a large number of military and non-military operations. When planning a helicopter flight during these operations, it is necessary to find more alternative routes, attack positions or landing zones. Good knowledge of the terrain and the associated awareness of the manoeuvring possibilities is an assumption for the successful discharge of the assigned tasks. For this reason, it is necessary to consider also a reconnaissance of the terrain when planning these operations. Terrain analyses processed by military geographers can provide various forms of results, such as verbal evaluations, thematic maps (Häusler, 2003; Mang and Häusler, 2006) or outputs of complex mobility models (Pokonieczny, 2017).

When searching for a suitable HLS, one of the possible outputs of the analysis is a thematic map showing areas suitable for landing. When using individual HLS given according to these thematic maps, it is common to subsequently verify the suitability of the selected HLS in the field (Kovarik, 2014; Kovarik and Rybansky, 2014). However, they are very beneficial for quick prediction of landing possibilities in a given operating area large scale.
A helicopter landing site is an area that serves for the safe landing and take-off of a helicopter (Civil Aviation Authority of the Czech Republic, 2018). In order to consider any area suitable for landing, a large number of parameters (factors) affecting the safe landing of helicopters must be considered. These parameters are based on the criteria given in STANAG 2999: Use of Helicopters in Land Operations (NSA, 2012).

\section{Factors influencing HLS Identifications}

Relief, water, vegetation, roads, settlements and soils are geographical elements fundamentally influencing the HLS identifications. In the following analysis, however, only the effect of the relief will take into account and the issue will be approached as if there were no other obstacles on the Earth's surface.

Over the years, the relief changes due to the geomorphological activity of water, glaciers and wind (erosion, sedimentation). It is often very rugged and has various microrelief shapes, such as boulders, ravines, potholes, embankments, etc. (Collins, 1998; Monkhouse, 1975; Rybansky and Lauermann, 2002). These shapes then become an obstacle to the landing of the helicopters. Information on the occurrence of microrelief shapes in a given area can be obtained from a detailed digital terrain model (Dohnal, 2020).

\subsection{Slope of Ground}

The main parameter of the relief, which fundamentally affects helicopters landing possibilities, is the slope of ground (Rybansky and Vala, 2009a; Rybansky and Vala, 2009b). Ii is important to identify areas with a uniform slope that should not exceed (NSA, 2012):

- $\quad$ an angle of $7^{\circ}$ (or 1:8) in any direction when landing during the day; 
- $\quad$ an angle of $3^{\circ}$ (or 1:20) of forward and/or lateral slope at night.

The above criteria can be reduced according to the type of operation, the capabilities of the helicopter, the experience of the pilot (NSA, 2012).

\subsection{Obstacles}

It is also important to deal with the modelling of possible terrain obstacles and assess the obstruction angle to this obstacles from the landing point on approach and exit paths according to the STANAG 2999 (NSA, 2012).

This angle is measured from the point where the approach and exit paths intersect the landing point area (Fig. 1). This angle should not exceed (NSA, 2012):

- angle $6^{\circ}$ to a distance of $500 \mathrm{~m}$ from the landing point during the day;

- angle $4^{\circ}$ to a distance of $3000 \mathrm{~m}$ from the landing point at night.

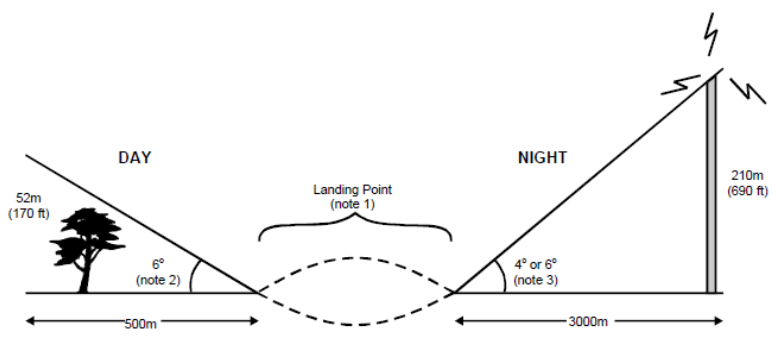

Figure 1: Landing point obstruction angle on approach and exit paths (NSA, 2012)

For daylight conditions, the maximum obstacle height is $52 \mathrm{~m}$ to $500 \mathrm{~m}$ from the landing point. At night, it is $210 \mathrm{~m}$ to a distance of $3000 \mathrm{~m}$.

\subsection{Landing Site Dimension}

Another irreplaceable part of the HLS identification is the evaluation if the landing site dimension and shape. The size of the HLS depends on the number and size of landing points within it and the dispersion required between individual landing points based on the tactical situation (NSA, 2012).

The regulation (NSA, 2012) states a total of 5 possible landing point dimensions, while in the case of choosing a circular shape of the landing point, it is possible to use all 5 of these dimensions. However, if the rectangular shape of the landing point is selected, it is only possible to select a dimension $3-5$. The exact dimensions and shapes of the landing points are shown in Fig. 2.
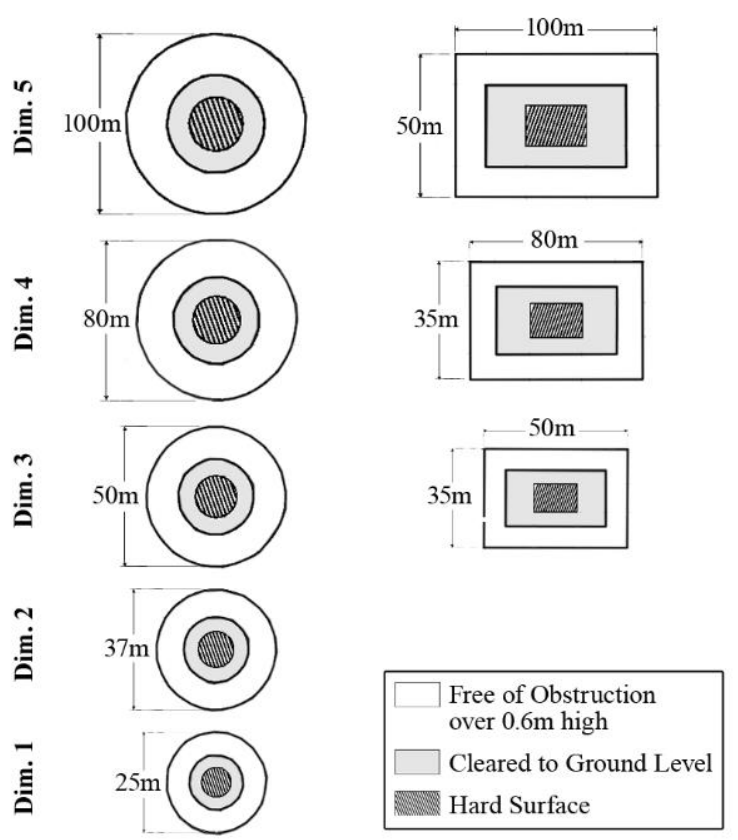

Figure 2: Helicopter landing point dimensions and shapes (NSA, 2012)

In case of landing more than one helicopter at the same time, it is also necessary to determine the minimum recommended distance between the centres of individual landing points. These distances, where no consideration to dispersion between helicopters is given, correspond to chosen dimension (NSA, 2012).

\section{Model Areas, Data and Software Availability}

To identify areas suitable for helicopter landings depending on the slope, landing site dimension and shape, three different model areas from the Czech Republic with a size of $1 \times 1 \mathrm{~km}$ were selected. The locations of territories with MGRS coordinates of the lower left corners can be seen in Fig. 3.

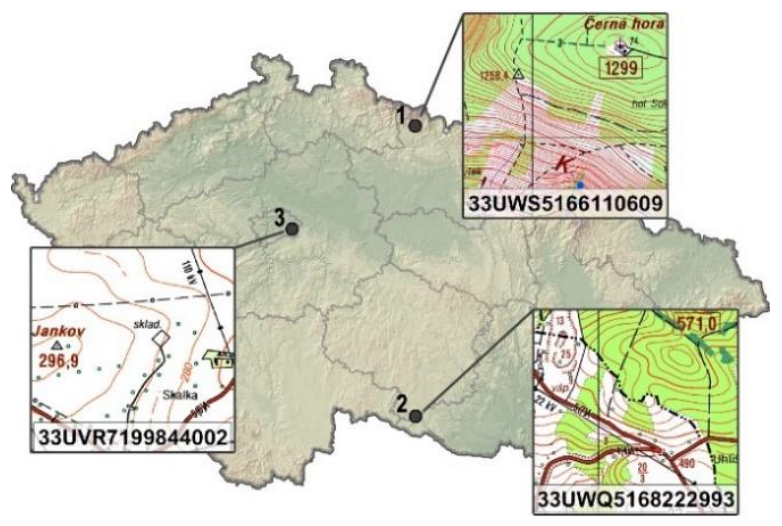

Figure 3: Localization of model areas with MGRS coordinates of the lower left corners of the area 
The area 1 represents mountainous terrain and is located near the state border with Poland in the area of the Krkonoše Mountains. The highest point in this area is $1299 \mathrm{~m}$ above sea level high, the lowest point reaches $961 \mathrm{~m}$. The average altitude is $1197 \mathrm{~m}$. The maximum slope is almost $45^{\circ}$, the average value is around $17^{\circ}$.

The second area is the rugged terrain, this time near the state border with Austria in the South Moravian Region. The highest altitude in area 2 reaches only $564 \mathrm{~m}$ above sea level, the average altitude is $498 \mathrm{~m}$ and the average slope of ground in the area is $7^{\circ}$.

The third area is a flat terrain located east of the capital city of Prague. The average altitude in area 3 is $283 \mathrm{~m}$, the maximum value is $297 \mathrm{~m}$ and the minimum value is $272 \mathrm{~m}$. The slope is on average $2^{\circ}$.

\subsection{Data Processing}

There are currently several digital terrain models from the Czech Republic which differ in their accuracy and data density and can be used in various military analyses. In recent years, several experiments focusing on digital elevation models in the Czech Armed Forces and examination of their accuracy have been carried out (Brenova, 2016; Hubacek, 2002; Hubacek and Vasicek, 2002; Hubacek et al., 2014; Hubacek et al., 2015; Hubacek et al., 2016; Kovarik, 2011; Miklosik and Vondra, 2011; Pokonieczny and Mościcka, 2018; Sobotka, 2013).

The results of the conducted experiments subsequently served as a principle for analysing the digital terrain models suitability for HLS identification. At the end of this analysis, it was concluded that the Digital terrain model of the Czech Republic $4^{\text {th }}$ generation (DTM4) with a spatial resolution of $25 \mathrm{~m}$ is the most effective for this type of analysis in terms of the accuracy of the results depending on the time required to evaluate the area (Mertova, unpublished).
DTM4 is a digital elevation model provided in the format of a regular grid of $5 \times 5 \mathrm{~m}$ with a total height mean error $0.3 \mathrm{~m}$ in uncovered terrain and $1 \mathrm{~m}$ in wooded terrain (Brazdil, 2012). The data for the following analysis was generated with a pixel size of $25 \mathrm{~m}$ and was cut using three clipping polygons representing selected model areas of $1 \times 1 \mathrm{~m}$. With modified input data, it was possible to proceed to the analysis of HLS identification depending on slope, landing site dimension and shape.

Data processing as well as the analysis itself was performed in ArcGIS 10.3.1, when the Integrated Development Environment (IDLE) was used to create a computational script.

\section{HLS Identification depending on the Slope of Ground}

In the course of the following analysis, only daylight conditions were considered.

First of all, the slope rasters were calculated and converted to a vector point layers. After that, points with an inclination greater than $7^{\circ}$ were filtered out to ensure that only areas with a satisfactory slope enter further analysis.

The next step was to identify possible occurrence of the terrain obstacles, which would make it impossible for helicopters to land. To assure that the vertical obstruction safe distance is observed, it was created a script, which assess whether the a maximum angle of $6^{\circ}$ to a possible terrain obstacle within a distance of $500 \mathrm{~m}$ from individual points is observed. If this condition was not met at any point, that point was deleted. Thus, a point layers that met the conditions for landing during the day considering the slope of ground and the occurrence of any terrain obstacles in the HLS were obtained and visualized as a potential HLS (Fig. 4).
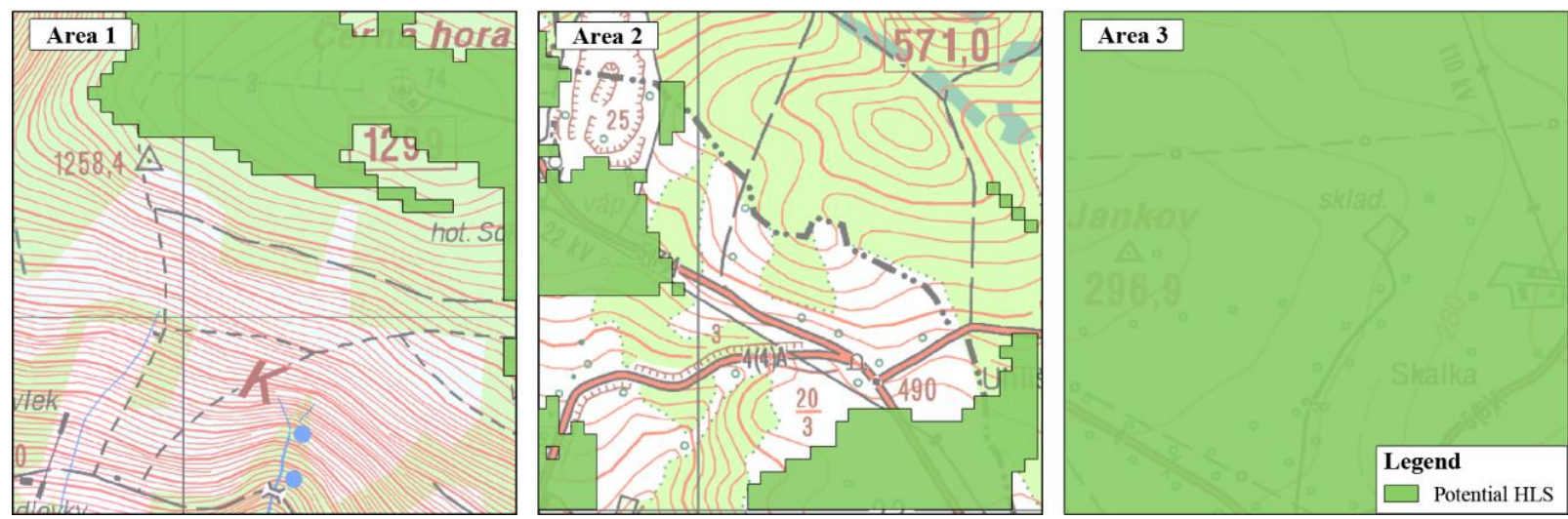

Figure 4: Potential HLS considering the slope of ground and the occurrence of any terrain obstacles 
In mountainous area 1 , due to the high values of the slope of ground, a total of $75 \%$ of the area was filtered out, in $3 \%$ of the area there was an occurrence of impassable terrain obstacle and the remaining $22 \%$ of the model area was assessed as a suitable area for helicopter landing (potential HLS).

In the case of area 2 - rugged terrain - due to the slope, $44 \%$ of the territory was inconvenient and in $37 \%$ of the territory there was an impassable terrain obstacle that would prevent a safe landing of the helicopter. As a result, only $20 \%$ of the model area was assessed as a potential HLS.

Flat area 3 was whole evaluated as an area suitable for landing.

\section{HLS Identification depending on the Dimension and Shape}

For more accurate results of landing possibilities in the area of potential HLS obtained by the analysis described
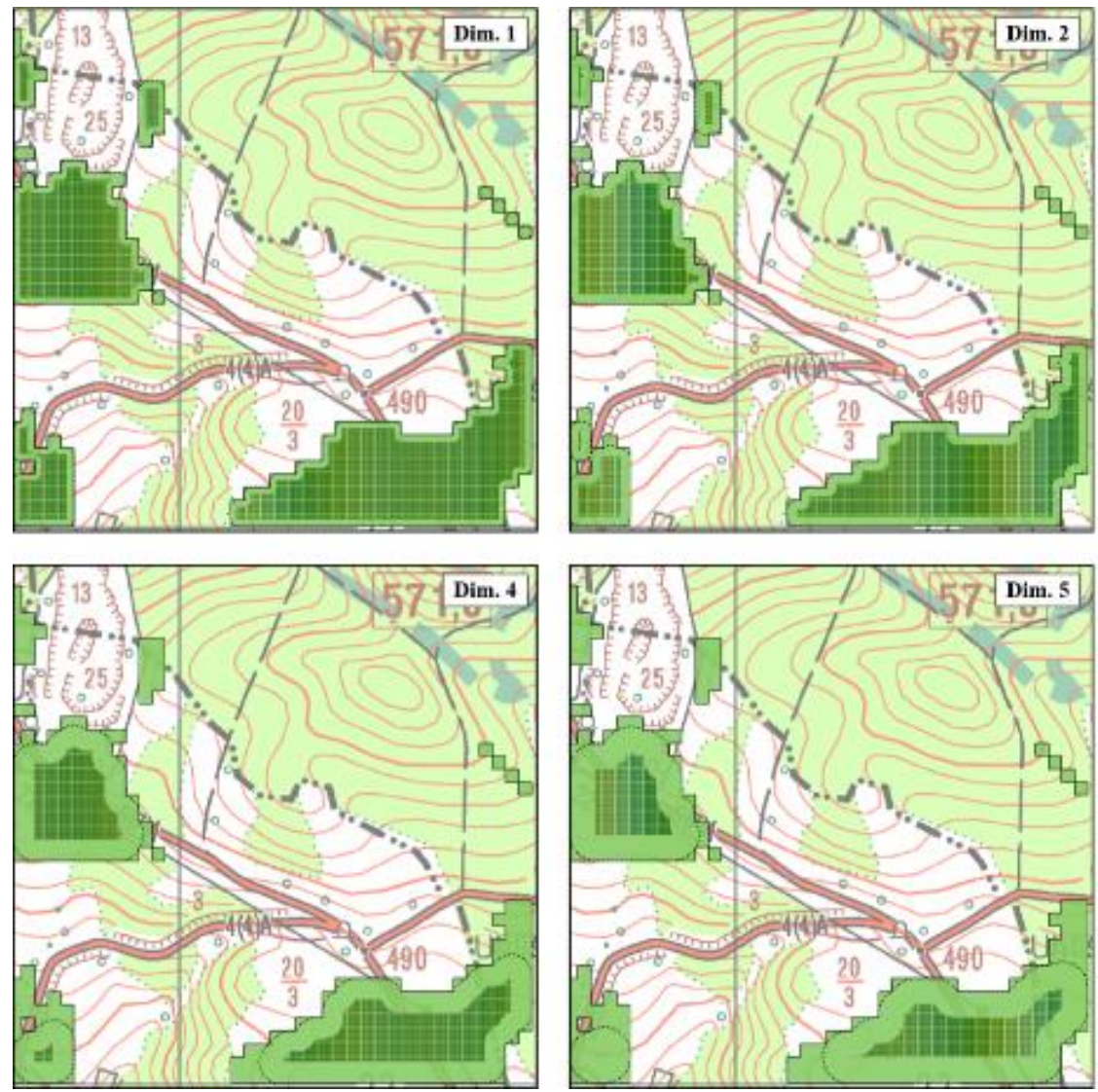

above, it was necessary to address the HLS dimension and shape, or to deal with the direction of the HLS (landing point orientation).

For this part of the analysis, it was also developed a tool, which allows the user to choose the size and shape of the landing point, according to which the calculation will be realized. The description of this tool can be divided into two parts depending on the shape of the landing point.

\subsection{Circular HLS}

When selecting the circular shape of the HLS, the buffer zone at a distance corresponding to the radius of the selected landing point size around potential HLS is calculated. After that, this buffer zone is cut from the polygon layer of the potential HLS and thus an area representing the set of centres of individual circular landing points in any direction is obtained - HLS all directions.

For simplicity, only the results of the calculation in area 2 were visualized in Fig. 5.

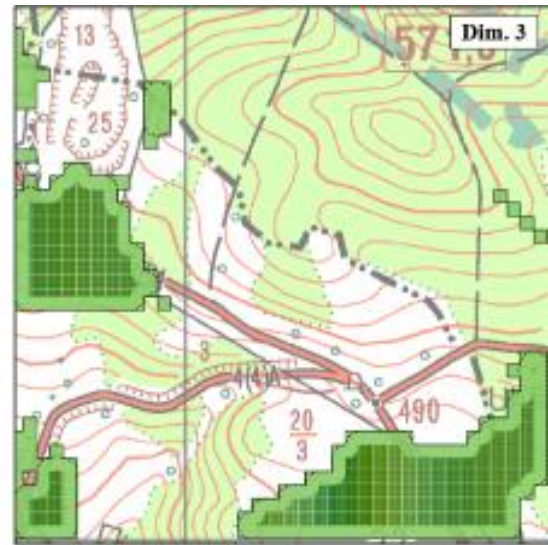

\section{Legend}

- HLS - all directions

Helicopter Landing Zone

Potential HLS

Figure 5: Circular HLS of individual dimensions in area 2

In Figure 5, Helicopter Landing Zones can also be seen. These zones were obtained by creating another buffer zone, this time around the area of the HLS all directions.
These buffer zones were created at the same distance as the size used to calculate the actual HLS (the radius of the selected landing point size). Helicopter Landing 
Zones in this case indicates the marginal boundary of the individual HLS.

\subsection{Rectangular HLS}

In the case of choosing the rectangular shape of the HLS, a total of 4 main landing directions were implemented to a computational tool. In each case the opposite direction can also be used (Fig. 6).

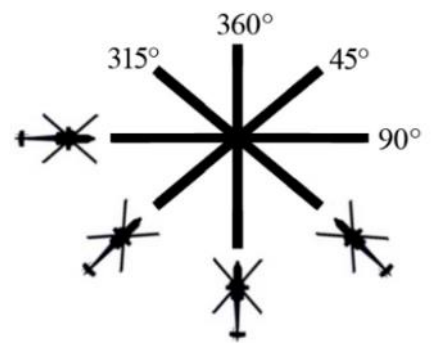

Figure 6: Basic landing directions

The first part of the computation is similar to the calculation of the circular shape. Nevertheless, this time there are a total of two buffer zones created. The first (smaller) distance corresponds to half the shorter side of the selected landing point size, the second (larger) distance corresponds to half the diagonal.

The buffer zone calculated using half the diagonal of the rectangle is then cut from the polygon layer of the potential HLS and thus again an area representing the set
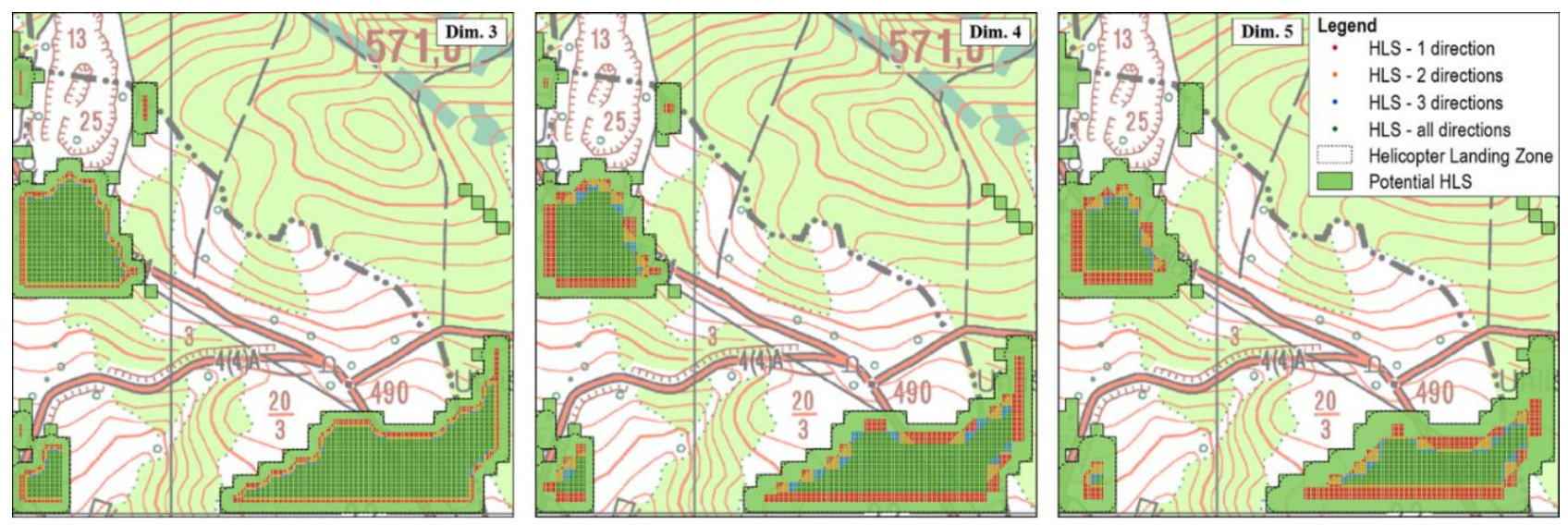

of centres of individual rectangular landing points in any direction is obtained - HLS all directions.

In the case of subtracting the buffer zone calculated using the half the shorter side of the rectangle from the polygon layer of the potential HLS and subsequent subtraction of the HLS all directions layer from the newly formed layer, a relatively narrow strip of territory can be obtained. This area represents a set of potential centres of individual rectangular landing points, which need to be further analysed in terms of the HLS orientation.

In this area, a regular grid of points with a step of $5 \times 5 \mathrm{~m}$ was generated. At these several points, rectangles of the selected landing point size oriented in all 4 examined directions are generated. Whether any of these rectangles intersect the line performing the boundary of the potential HLS, landing in such direction is at this point inadmissible. If the generated rectangle does not intersect this line at any point, this landing direction is allowed and this information is written to the attribute table. The result of this calculation is a set of points that have information about possible helicopter landing directions in the attribute table (HLS 1, 2, 3 directions).

The results of the calculation and the Helicopter Landing Zones in area 2 were visualized in Fig. 7.

Figure 7: Rectangular HLS of individual dimensions in area 2

\section{Conclusion}

The main result of the conducted analysis is the development of a tool for the HLS identification, taking into account the effect of relief depending on the slope, landing site dimension and shape and also the orientation of the HLS. This tool requires a suitably adjusted digital terrain model at the input. For large- 
are considered. This should be the subject of the further analysis. Another idea of a possible improvement of the developed tool is the possibility to choose landing direction depending on the prevailing wind direction in the computational area. Related to that, another disputable issue is the evaluation of the influence of the meteorological conditions on the HLS.

The outputs of this tool, after its future refinement, could be used during the operation planning process, but it should always be kept in mind that the results obtained are only theoretical and the ultimate decision of use of the selected HLS rest with the helicopter commander or formation leader.

\section{References}

[1] Brazdil, K. et al.: Technical report to the digital terrain model DTM $4^{\text {th }}$ generation, Pardubice, Dobruska, Zememericky urad, VGHMUR, 11 p, 2012.

[2] Brenova, M.: The analysis of the influence of geographical and meteorological elements on observation and concealment, Brno: University of Defence, 2016.

[3] Civil Aviation Authority of the Czech Republic: Aviation Directive L 14H (Heliports), Ministry of Transport of the Czech Republic, 2018.

[4] Collins, J. M.: Military Geography for Professionals and the Public, Washington, D.C.: Potomac Books, Inc., 1998.

[5] Dohnal, F.: Modelling the impact of drainage on the military vehicles mobility, Brno: University of Defence, 2020.

[6] Häusler, H.: Wehrgeologie im nordafrikanischen Wüstenkrieg (1941-1943) (Military Geology in the Desert War of Northern Africa 19411943), MILGEO, vol. 13m Wien: Federal Ministry of Defence, 135 p, 2003.

[7] Hubacek, M.: Methods of military geographical analyses in Czech Army, Brno: Military academia Brno, 2002.

[8] Hubacek M. and Vasicek, M.: Elevation models in the Army and their use, Vojensky geograficky obzor, no. 1, pp. 40-47, 2002.

[9] Hubacek M. et al.: Verification of Accuracy of the New Generation Elevation Models, Advances in Military Technology, vol. 9, no. 2, Brno: University of Defence, pp. 21-32, ISSN: 1802-2308, 2014.
[10] Hubacek M. et al.: Accuracy of the new generation elevation models, Proceedings of the International Conference on Military Technologies 2015 (ICMT'15), Brno: University of Defence, pp. 289-294, ISBN: 978-80-7231-976-3, 2015.

[11] Hubacek M. et al.: Analysis of influence of terrain relief roughness on DEM accuracy generated from LIDAR in the Czech Republic territory, International Archives of the Photogrammetry, Remote Sensing and Spatial Information Science-ISPRS Archives, vol. 41, pp. 25-30, ISSN 1682-1750, 2016.

[12] Kovarik, V.: Possibilities of geospatial data analysis using spatial modeling in ERDAS IMAGINE, Proceedings of the International Conference on Military Technologies 2011 (ICMT'11), Brno: University of Defence, pp. 1307-1313, 2011.

[13] Kovarik, V.: Use of Spatial Modelling to Select the Helicopter Landing Sites, Advances in Military Technology, vol. 9, no.1, Brno: University of Defence, pp. 69-79, 2014.

[14] Kovarik V. and Rybansky M.: Selecting locations for landing of various formations of helicopters using spatial modelling, 2014. [Online]. [cit. 2019-01-06]. Available from: <http://iopscience.iop.org/article/ 10.1088/17551315/18/1/012132/pdf>.

[15] Mang R. and Häusler H.: International Handbook Military Geography, Wien: AV + Astoria Druckzentrum, 591 p, ISBN 3901183507, 9783901183508, 2006.

[16] Mertova, E.: Digital terrain models suitability for helicopter landing sites identification, unpublished.

[17] Miklosik F. and Vondra, D.: Precision elevation models in the Czech Republic, Vojensky geograficky obzor, no. 3, pp. 17-21, 2001.

[18] Monkhouse, F. J.: Principles of Physical Geography, 8th ed.. London: Hodder and Stoughton Ltd., ISBN 0340050624, 9780340050620, 1975.

[19] NSA: STANAG 2999: Use of Helicopters in Land Opertions, Brussels: NATO Standardization Agency, 2012.

[20] Pokonieczny, K.: Automatic military passability map generation system, Proceedings of the International Conference on Military Technologies 2017 (ICMT'17), Brno: University of Defence, pp. 285-292, 2017. 
[21] Pokonieczny K. and Mościcka, A.: The Influence of the Shape and Size of the Cell on Developing Military Passability Maps, ISPRS International Journal of Geo-Information, vol. 7, no. 7, pp. 261, https://doi.org/10.3390/ijgi7070261, 2018.

[22] Rybansky M. and Lauermann, L.: Military Geography, Prague: Ministry of Defence of the Czech Republic, ISBN: 80-238-9274-6, 2002.

[23] Rybansky M. and Vala, M.: Analysis of relief impact on transport during crisis situations, Moravian Geographical Reports, vol. 17, no. 3, pp. 19-26, 2009a.

[24] Rybansky M. and Vala, M.: Relief Impact on Transport, Proceedings of the International Conference on Military Technologies 2009 (ICMT'09), Brno: University of Defence, pp. 551-559, 2009b.

[25] Sobotka, J.: Comparison of elevation data of the Czech Republic for design military constructions, Advances in Military Technology, vol. 7, no.2, Brno: University of Defence, pp. 57-63, ISSN 1802-2308, 2013 